\title{
RGB色空間の境界色を用いたカラー画像のコントラスト強調 \\ Contrast Enhancement of Color Images with Boundary Colors in RGB Color Space
}

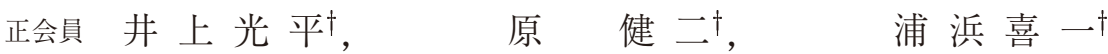

Kohei Inoue $^{\dagger}$, Kenji Hara ${ }^{\dagger}$ and Kiichi Urahama ${ }^{\dagger}$

\begin{abstract}
We propose a method for enhancing the contrast of color images by transforming the original colors into the colors on the boundary of RGB color space. Experimental results show that the proposed method generates colorful and contrast-enhanced images.
\end{abstract}

キーワード : contrast enhancement, color image, RGB color space, variance maximization

\section{1.まえがき}

近年，ディジタル映像機器の普及に伴い，より高度なカ ラー画像のコントラスト強調法が求められている ${ }^{1)}$. グレー スケール画像を対象とする方法を，カラー画像の各成分 (例 えば，RGB 色空間であれば，RGBの各成分) に，もしく は，輝度成分のみに施すというのが簡単な方法であるが，そ うすると, 各成分の相関関係が乱される場合がある。そこ で，マルチチャネル信号処理が必要になる。カラー画像処 理では，色空間を処理に適したものに変換するという方法 も考えられるが，最終的には RGB 色空間に戻さねばなら ず，その結果が元の RGB 色空間からはみ出してしまう場 合があるという難点がある. Han ら ${ }^{2)}$ は，グレースケール 画像のヒストグラムを均等化するようなカラー画像のコン トラスト強調法を提案した. Naik $5^{3)}$ も，色相を保存し ながらカラー画像を強調する, 同様の手法を提案している.

本論文では，RGB 色空間の境界色を用いることによっ て，RGB 色空間における画素值の分散を最大化するよう なコントラスト強調法を提案し, 鮮やかな色合いのコント ラスト強調画像が得られることを実験で示す。また，提案 手法と従来手法とを組合せた方法も提案し, さらにコント ラストを強調できることを実験で示す。

\section{2. 提 案 手 法}

縦方向の画素数を $m$ とし, 横方向の画素数を $n$ とす るカラー画像を $f=\left[f_{i j}\right], f_{i j}=\left(f_{i j}^{R}, f_{i j}^{G}, f_{i j}^{B}\right), i=$

2011 年 11 月 17 日受付, 2012 年 5 月 11 日採録

†九州大学 大学院芸術工学研究院 コミュニケーションデザイン科学部門

(テ 815-8540 福岡市南区塭原 4-9-1, TEL 092-553-4512)

$\dagger$ Department of Communication Design Science, Faculty of Design, Kyushu University

(4-9-1, Shiobaru, Minami-ku, Fukuoka-shi, 815-8540 Japan)
$1, \ldots, m ; j=1, \ldots, n$ とする。ここで $f_{i j}$ は，画素 $(i, j)$ の RGB 值 $f_{i j}^{R}, f_{i j}^{G}, f_{i j}^{B}$ を要素とするべクトルであり, 各要 素の取り得る值は, $f_{i j}^{X} \in\{0,1, \ldots, 255\}, X \in\{R, G, B\}$ とする，RGB 色空間の概念図を図 1 に示す. RGB 色空間 は立方体で表すことができ，その中の 1 点が一つの色に対 応する. 本論文では，この立方体の表面上の点に対応する色 を境界色と呼ぶことにする. RGB 色空間の 2 点 $(0,0,0)$ と $(255,255,255)$ を結ぶ線分上の点を $p(\alpha)=\alpha(1,1,1), \alpha \in$ $[0,255]$ とし,

$$
\tilde{f}_{i j}=t\left[f_{i j}-p(\alpha)\right]+p(\alpha)
$$

によって， $f_{i j}$ を RGB 色空間の境界の色 $\tilde{f}_{i j}$ に変える。す なわち, RGB 色立方体の 2 頂点 $(0,0,0)$ と $(255,255,255)$ を結ぶ線分上の 1 点から, RGB 色空間中の 1 点 $f_{i j}$ に向か うベクトルを伸ばしていき，RGB 色立方体の表面と交わ る点を求める。 (1) 式の $t$ は変数であり, ベクトルの一つの 要素を取り出すと, $\tilde{f}_{i j}^{X}=t\left(f_{i j}^{X}-\alpha\right)+\alpha$ より

$$
t\left(\tilde{f}_{i j}^{X}\right)=\frac{\tilde{f}_{i j}^{X}-\alpha}{f_{i j}^{X}-\alpha}
$$

と表される。 $\tilde{f}_{i j}^{X}$ を境界色にするには,

$$
\begin{array}{r}
t_{i j}=\min _{\tilde{f}_{i j}^{X} \in\{0,255\}, X \in\{R, G, B\}} t\left(\tilde{f}_{i j}^{X}\right) \\
\text { subj.to } t\left(\tilde{f}_{i j}^{X}\right) \geqq 0
\end{array}
$$

によって $t$ の值を求めればよい. (4) 式の制約条件は, RGB 色立方体表面に向かって伸ばすべクトルの向きが反転する のを禁ずるためのものであり，(3) 式の最小化は， $f_{i j}$ に最 も近い平面を選択することを意味する。これにより， $f_{i j} に$ 最も近い境界色が求まる。すべての画素において，(3) 式 の $t_{i j}$ を (1) 式の $t$ に代入して $\tilde{f}_{i j}$ を計算すると, RGB 色 


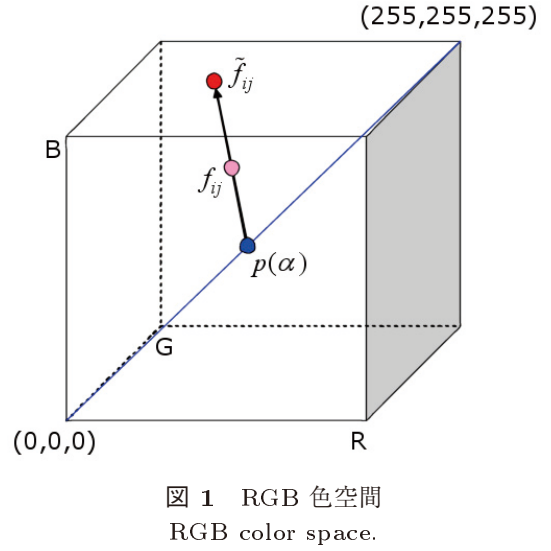

空間の境界色のみで構成される画像 $\tilde{f}(\alpha)=\left[\tilde{f}_{i j}(\alpha)\right]$ が得 られる。

次に， $\alpha$ の值を決める方法を考える。ここでは， $\alpha$ の值 を自動的に決めるための方法の一つとして，RGB 色空間 における $\left\{\tilde{f}_{i j}(\alpha)\right\}$ の分散が最大になるような $\alpha$ を求める 方法を提案する。すなわち，

$$
\max _{\alpha} \frac{1}{m n} \sum_{i=1}^{m} \sum_{j=1}^{n}\left\|\tilde{f}_{i j}(\alpha)-\bar{f}(\alpha)\right\|^{2}
$$

を解く.ここで, $\bar{f}(\alpha)=\frac{1}{m n} \sum_{i=1}^{m} \sum_{j=1}^{n} \tilde{f}_{i j}(\alpha)$ である.

\section{3. 実 験 例}

実験に用いた画像を図 2(a)-(c) に示す。図 2(a)，(b)の 画素数は $512 \times 512$ であり, 図 2 (c) の画素数は $256 \times 256$ である.Han らの手法 ${ }^{2)}$ による結果を図 2(d)-(f) に示し， Paint Shop Pro ver. 7.04 のヒストグラム平均化の結果を 図 $2(\mathrm{~g})-(\mathrm{i})$ に示す。提案手法に拈いて， $\alpha$ の值を 0.5 刻み で変えたときの分散 ((5) 式)の值の変化を図 3 に示す. 縦 軸は分散であり，横軸は $\alpha$ である。図中の実線，破線，点 線はそれぞれ図 2(a), (b), (c) に対応し, 分散が最大となる $\alpha$ の值はそれぞれ $\alpha=147.0,128.5,99.5$ であった。この ときの画像 $\tilde{f}(\alpha)$ をそれぞれ図 $2(\mathrm{j}),(\mathrm{k}),(\mathrm{l})$ に示す。これ らの画像は, RGB 色空間の境界色で構成されているため, 元画像 (図 2(a)-(c)) や従来手法による結果 (図 2(d)-(i)) と 比較すると，色がより鮮やかであり，また，明るい画素は より明るく，暗い画素はより暗くなっており，コントラス トも強調されている。 このように提案手法では, 鮮やかな 色合いのコントラスト強調画像が得られる。

次に, Han らの手法 ${ }^{2)}$ と提案手法を組合せたときの結 果を図 4 に示す. 図 4(a)-(c) は提案手法を行った後にHan らの手法 ${ }^{2)}$ を行った結果であり, 図 4(d)-(f) は 2 手法の順 序を変えたときの結果である。このように，二つの手法を 組合せることによって，ささらにコントラストを強調するこ ともできる。各画像の RGB 色空間に抒ける分散を表 1 に 示す. 表中の Comb. 1, 2 は, 上述の Han らの手法 ${ }^{2)}$ と提 案手法を組み合わせた 2 手法を表している。 どの画像でも， Comb. 2 で分散が最大になった。 また, どの手法でも, 元

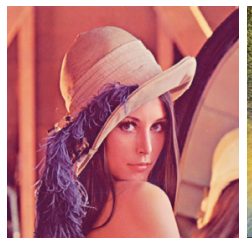

(a)

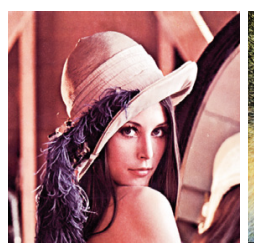

(d)

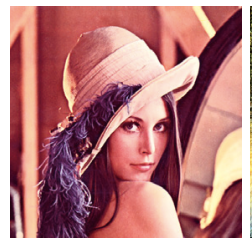

(g)

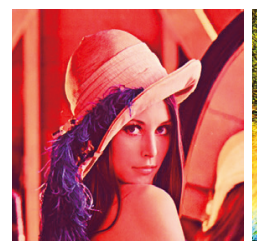

(j)

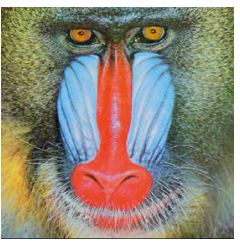

(b)

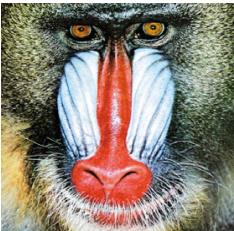

(e)

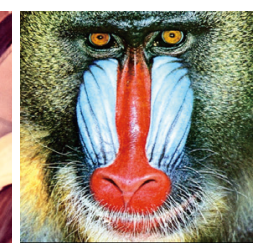

(h)

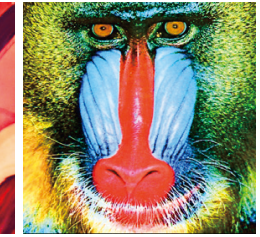

(k)

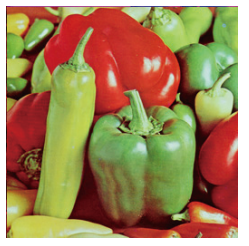

(c)

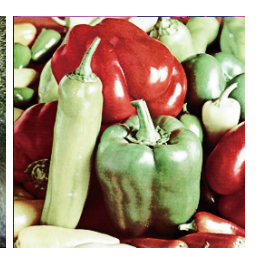

(f)

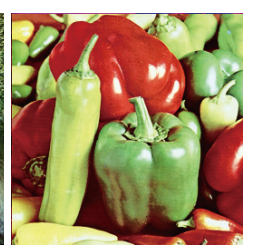

(i)

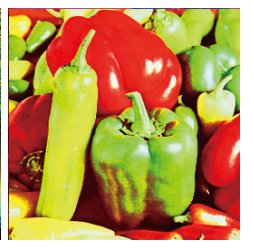

(1)
図 2 元画像: (a) Lena, (b) Mandrill, (c) Pepper と, コン トラスト強調の結果: (d)-(f) Han らの手法 ${ }^{2)}$, (g)-(i) Paint Shop Pro, (j)-(1) 提案手法

Original images: (a) Lena, (b) Mandrill and (c) Pepper, and the corresponding results: (d)-(f) by Han's method ${ }^{2)}$, (g)-(i) by Paint Shop Pro and (j)-(l) by the proposed method.

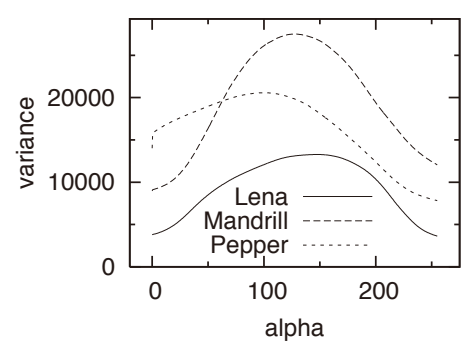

図 3 分散と $\alpha$ の関係

Variance vs. $\alpha$.

の画像よりも分散が大きなコントラスト強調画像が得られ ていることから, RGB 色空間に扔ける分散の值を, カラー 画像のコントラスト強調の定量的評価の一指標として利用 できるのではないかと考えている.

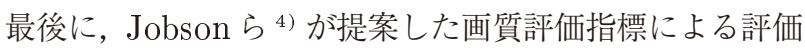
結果を示す. Jobson らの画質評価指標 ${ }^{4)}$ は次のように定義 される.まず，画像の平均明度を $I$ とする。ここでは, $g_{i j}=$ $0.2989 f_{i j}^{R}+0.5870 f_{i j}^{G}+0.1140 f_{i j}^{B}$ によって $f$ のグレース ケール画像 $g=\left[g_{i j}\right]$ を求め, $I=\frac{1}{m n} \sum_{i=1}^{m} \sum_{j=1}^{n} g_{i j}$ と 


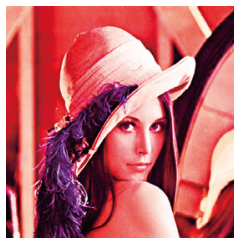

(a)

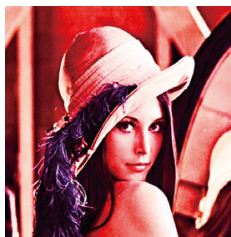

(d)

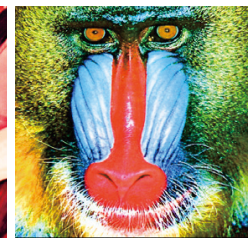

(b)

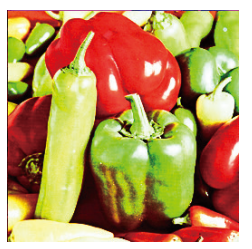

(c)

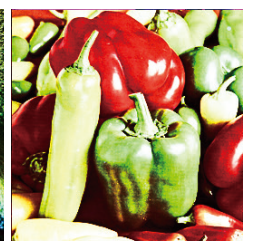

(f)
図 4 Han らの手法 ${ }^{2)}$ と提案手法を組み合わせた結果: (a)-(c) 提案手法の後に Han らの手法 ${ }^{2)}$ を行った結果，(d)-(f) Han らの手法 ${ }^{2)}$ の後に提案手法を行った結果

Results of the combined methods: (a)-(c) Han's method ${ }^{2)}$ after the proposed one, (d)-(f) the proposed method after Han's one ${ }^{2)}$

表 1 RGB 色空間における分散 $\left(\times 10^{2}\right)$ Variance in RGB color space. $\left(\times 10^{2}\right)$

\begin{tabular}{c|c|c|c}
\hline \hline & Lena & Mandrill & Pepper \\
\hline Original (Fig. 2(a)-(c)) & 63.95 & 93.07 & 97.30 \\
Han's method (Fig. 2(d)-(f)) & 172.79 & 188.01 & 185.56 \\
Paint Shop Pro (Fig. 2(g)-(i)) & 143.67 & 196.33 & 156.86 \\
Proposed (Fig. 2(j)-(l)) & 132.73 & 275.08 & 205.68 \\
Comb. 1 (Fig. 4(a)-(c)) & 200.34 & 251.33 & 241.96 \\
Comb. 2 (Fig. 4(d)-(f)) & $\mathbf{2 6 3 . 4 9}$ & $\mathbf{3 4 2 . 9 3}$ & $\mathbf{2 8 4 . 9 3}$ \\
\hline
\end{tabular}

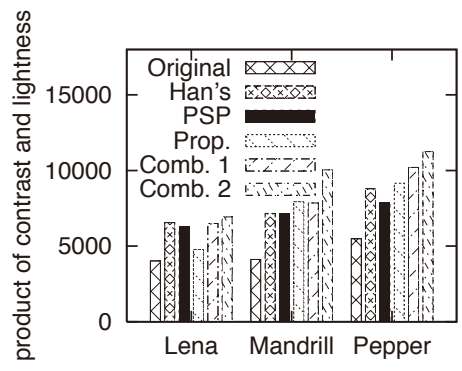

図 5 Jobson らの画質評価指標 ${ }^{4}$

The quality of visual representation by Jobson et al. ${ }^{4}$.

した。次に，画像 $g$ を重なりのない $50 \times 50$ 画素のブロッ クに分割し，各ブロックで明度の標準偏差 $\sigma_{k l}$ を求め，そ の平均を $\sigma=\frac{1}{K L} \sum_{k=1}^{K} \sum_{l=1}^{L} \sigma_{k l}$ とする.ここで， $K$ は 縦のブロック数であり，Lは横のブロック数である。たた し，画像の左上からブロックを配置していき，右端と下端 で画像からはみ出したブロックは除外して計算した。この とき，Jobson らの画質評価指標 ${ }^{4)}$ は，I $I \sigma$ で定義され，こ の值が大きいほど画質がよいとされる，各画像で $I \sigma$ の值 を計算した結果を図 5 に示す。縦軸は $I \sigma$ の值であり，横 軸には, Lena, Mandrill, Pepperの各画像に関して, 元 画像 (Original), Han らの手法 ${ }^{2)}$ (Han), Paint Shop Pro (PSP), 提案手法 (Prop.), 組合せ手法 1 (Comb. 1), 組 合せ手法 2 (Comb. 2) の 6 項目を順に並べている. Lena の画像では，提案手法 (Prop.) の值が小さいが，その他で
は提案手法や組合せ手法 1,2 (Comb. 1, 2) によって高い $I \sigma$ 值が得られた。

\section{4. むす び}

カラー画像を構成する各画素の色を RGB 色空間の境界 の色に変えることによって，色を鮮やかにするコントラス 卜強調法を提案し，Jobson らの画質評価指標 ${ }^{4)}$ による定 量的評価を行った。今後は, HDR 合成画像やスーパーリ アリズム絵画などに見られる鮮やかな色合いの生成に提案 手法を利用することを検討したい.

\section{〔文〔献〕}

1）田口亮: “カラー画像・映像の復元・強調に関する研究の現状”, Fundamentals Review, 3, 2, pp. 54-64 (2009)

2) J.-H. Han, S. Yang, and B.-U. Lee: "A novel 3-D color histogram equalization method with uniform 1-D gray scale histogram", IEEE Trans. Image Processing, 20, 2, pp. 506-512 (2011)

3) S. K. Naik and C. A. Murthy: "Hue-preserving color image enhancement without gamut problem", IEEE Trans. Image Processing, 12, 12, pp. 1591-1598 (2003)

4) D. J. Jobson, Z. Rahman, and G. A. Woodell: "The statistics of visual representation", in Visual Information Processing (2002)

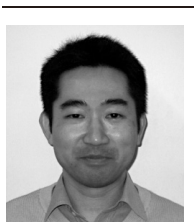

井上光光平 1996 年, 九州芸術工科大学画像設計 学科卒業. 2000 年, 同大学大学院博士後期課程修了. 現 在, 九州大学大学院芸術工学研究院助教. パターン認識, 画像処理，コンピュータビジョンに関する研究に従事．正 会員.

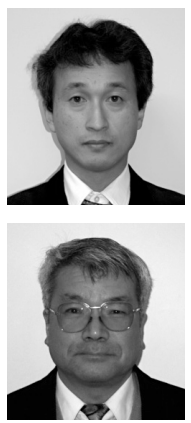

原花二じ 1989 年, 京都大学大学院工学研究科 修士課程修了。同年, 武田薬品工業 (株) 入社. 1991 年, 福岡県工業技術センター入所. 2001 年, 東京大学生産技 術研究所協力研究員. 現在, 九州大学大学院芸術工学研 究院准教授. コンピュータビジョン，画像処理に関する 研究に従事. 博士 (工学).

浦浜喜いち 1980 年, 九州大学大学院工学研究科 博士後期課程修了. 同年, 同大学助手. 1989 年, 九州工 業大学助教授. 現在, 九州大学大学院芸術工学研究院教 授.パターン認識, 画像情報処理の研究に従事。 